\title{
THE STUDY OF ANTICORROSIVE COLD SPRAYED AI-Zn COATINGS FOR Nd-Fe-B PERMANENT MAGNETS
}

\author{
${ }^{1}$ Igor BELYAEV, ${ }^{2}$ Kirill FROLOV, ${ }^{2}$ Aleksey STEPNOV, ${ }^{3}$ Viacheslav BAZHENOV, ${ }^{1}$ Andrey KIREEV \\ ${ }^{1}$ Vladimir State University named after Alexander and Nikolay Stoletovs, Vladimir, Russia, \\ belyaev-iv54@yandex.ru \\ 2Plasma Deposition Center, Co. Ltd., Vladimir, Russia, stepnov86@mail.ru \\ ${ }^{3}$ National University of Science and Technology MISiS, Moscow, Russia, v.e.bagenov@gmail.com \\ ${ }^{4}$ Baikov Institute of Metallurgy and Materials Science, Russian Academy of Sciences, Moscow, Russia, \\ imet@ultra.imet.ac.ru
}

https://doi.org/10.37904/metal.2020.3560

\begin{abstract}
Anticorrosive Al-Zn coatings applied on Nd-Fe-B permanent magnets were studied. The coatings were deposited on the surface of permanent magnets by high-speed cold spraying using various temperature conditions. The coatings were studied by optical metallography, scanning electron microscopy (SEM), quantitative X-ray diffraction analysis, and modern techniques for the estimation of adhesive strength of coatings. To determine the protective properties of Al-Zn coatings, salt spray corrosion tests were performed. The properties of the cold sprayed Al-Zn coatings are found to depend on the temperature of spraying. The coatings prepared at a spraying temperature of $200^{\circ} \mathrm{C}$ exhibit the best results. The increase in the deposition temperature above $200{ }^{\circ} \mathrm{C}$ leads to the increase in the content of large corundum particles in the coatings, which result in the embrittlement of the coating material.
\end{abstract}

Keywords: Rare-earth magnets, anticorrosive coatings, cold spraying, temperature of spraying, properties of coating

\section{INTRODUCTION}

Sintered rare-earth permanent magnets manufactured of $\mathrm{Nd}$-Fe-B-based alloys are characterized by the highest hysteretic properties as compared to those of magnets manufactured from the other available hard magnetic materials. This fact determines the wide application of these magnets in practice [1-3]. The main disadvantage of these magnets consists in their low corrosion resistance. To avoid this weakness, purposemade anticorrosive coatings are applied on the surface of Nd-Fe-B magnets [4-7]. Earlier it was found that aluminum-zinc coatings applied on the magnet surface by cold spraying ensure the best corrosive protection of these magnets. From here in, the coatings will referred to as cold sprayed coatings. It was found also that the required protective properties of coating are reached when the coating thickness becomes equal to $30 \mu \mathrm{m}$. Data on the technology of application of such coatings and properties, which are ensured the coatings, are available in [7, 8]. However, the role of temperature conditions of spraying is not well understood.

In the present study, we investigate the effect of temperature conditions of cold spraying of aluminum-zinc coatings on the efficiency of corrosion protection of $\mathrm{Nd}-\mathrm{Fe}-\mathrm{B}$-based magnets and on the microstructure, phase composition, adhesive strength of the coatings as well..

\section{EXPERIMENTAL}

The studies were performed using sintered rectangular permanent magnets $10 \times 20 \times 5 \mathrm{~mm}$ in size, which were prepared from $\mathrm{Nd}-\mathrm{Fe}-\mathrm{B}-$ based alloy by standard powder metallurgy technology $[1,3]$. The chemical 
composition of the magnet material includes $32.5 \% \mathrm{Nd}, 2.5 \% \mathrm{Dy}, 3.0 \% \mathrm{Co}, 1.2 \% \mathrm{~B}$ (wt \%), and Fe balance. From here in, the composition is given in wt \%.

To apply the coating, we used powder material of grade A-20-11, which contains $30 \pm 5 \% \mathrm{Al}, 45 \pm 5 \% \mathrm{Zn}$ and $25 \pm 5 \% \mathrm{Al}_{2} \mathrm{O}_{3}$ (corundum). The corundum was added to the powder mixture as the process agent.

The cold spraying was realized using a Dimet-405 installation (Russia). We used five temperature spraying regimes: $100{ }^{\circ} \mathrm{C}, 200^{\circ} \mathrm{C}, 300^{\circ} \mathrm{C}, 400^{\circ} \mathrm{C}$, and $500^{\circ} \mathrm{C}$. All other spraying parameters were the same: the air pressure in the system is $5.5-6 \mathrm{~atm}$; the spraying distance is $13 \mathrm{~mm}$; the velocity of nozzle travel with respect to the sprayed surface is $8 \mathrm{~mm} / \mathrm{s}$; and the powder material consumption is $1 \mathrm{~g} / \mathrm{mm} 2$.

Metallographic studies were performed using a Raztec MRX9-D (Russia) optical microscope and a Tescan Vega 3 SBH (Czech Republic) scanning electron microscope (SEM) equipped with an Oxford (USA) energy dispersive X-Ray spectroscopy (EDS) analyzer.

The chemical composition of alloys was determined using an ARL Advant'X (USA) standard-less fluorescent spectrometer.

To perform the quantitative phase analysis, a D8 Advance (Bruker AXS, Germany) diffractometer was used. The studies were performed using CuKa radiation. The data were processed using TOPAS software.

The adhesion strength tests were performed by Scratch method using a Micro-Combi Tester (Switzerland). The measurements were carried out under loading continuously increased from 0 to $25 \mathrm{~N}$. A Rockwell diamond indenter with an apex radius of $100 \mu \mathrm{m}$ was used.

Corrosion tests were performed in two stages. All samples used for the corrosion tests had a coating $30 \mu \mathrm{m}$ in thickness. The first stage of tests was carried out in a KST-1 salt spray chamber at a temperature of $35 \pm 2{ }^{\circ} \mathrm{C}$ for $96 \mathrm{~h}$. The salt solution was automatically injected into the chamber each $15 \mathrm{~min}$. The sodium chloride $(\mathrm{NaCl})$ concentration in the salt solution was $50 \pm 5 \mathrm{~g} / \mathrm{l}$. The second stage of the test was performed using a dessicator with an open vessel filled with the $\mathrm{NaCl}$ solution and located on the bottom of dessicator. The time of the tests was 30 days. Corrosion damages during the first and second stages of the tests were estimated by visual inspection performed once a day at the same time.

\section{RESULTS AND DISCUSSION}

Metallographic analysis of samples cross-sections sprayed at $100-500^{\circ} \mathrm{C}$ showed that, in all cases, the coating adjoins densely the substrate surface. Figure 1 shows micrographs of cross-sections of samples with cold sprayed Al-Zn coatings applied at 100,300 and $500{ }^{\circ} \mathrm{C}$.
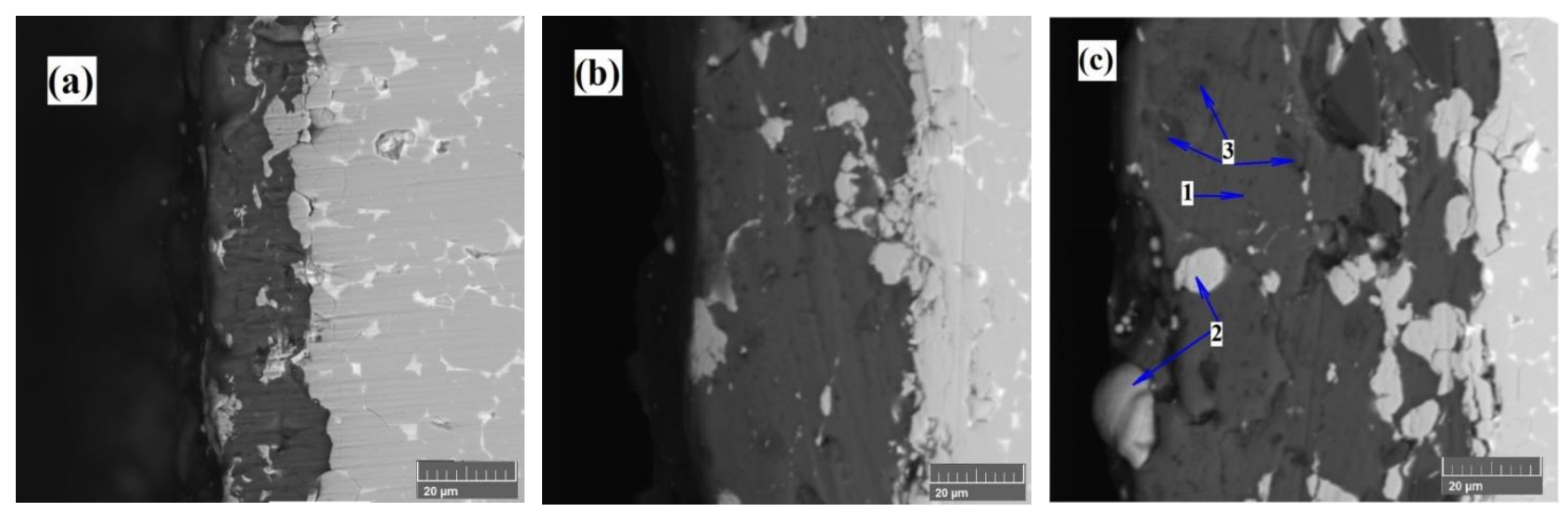

Figure 1 Micrographs (SEM) of cross-sections of samples with cold sprayed aluminum-zinc coatings deposited at spraying temperature: (a) 100 , (b) 300 , and (c) $500^{\circ} \mathrm{C}$ 
It is seen that, as the spraying temperature increases, the coating thickness increases despite of the fact that all process parameter, except temperature, were the same. Figure 2 shows the dependence of the coating thickness on the spraying temperature.

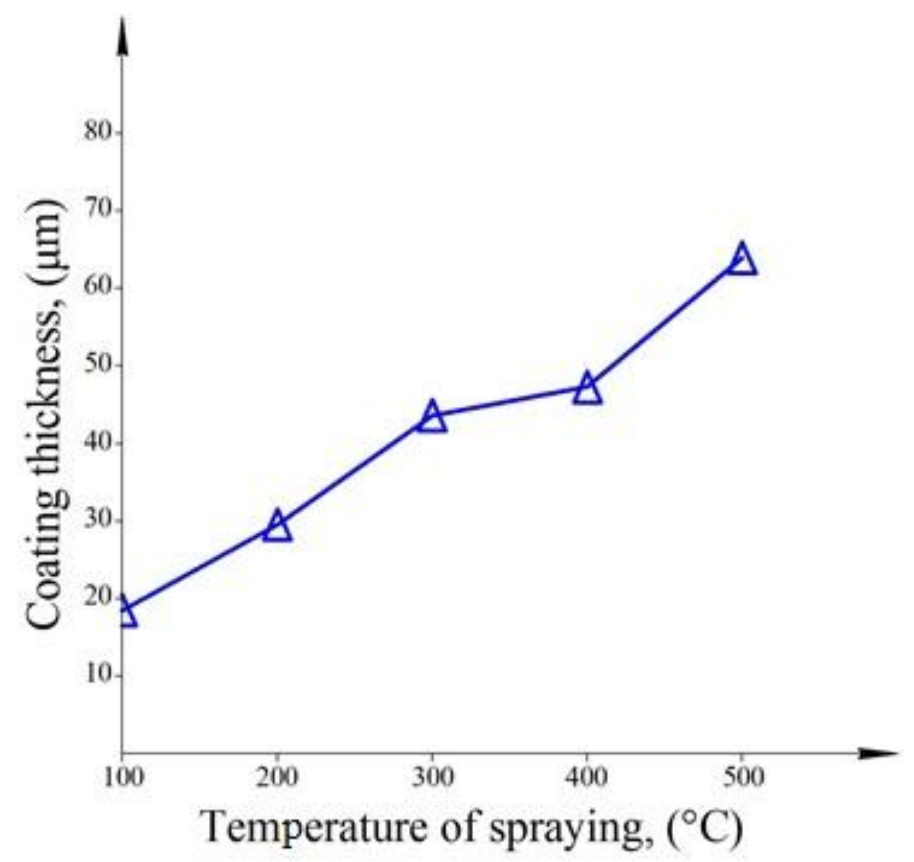

Figure 2 Influence of the spraying temperature on cold sprayed aluminum-zinc coating thickness

The performed studies allowed us to find that, during spraying at $100{ }^{\circ} \mathrm{C}$, a large part (more than a half) of sprayed coating is not consolidated on the substrate and peels of the surface and blows away the substrate surface. As the spraying temperature increases, the fixation of sprayed powder material on the substrate surface increases. This is likely to be the cause for the increase in the coating thickness when passing from 100 to $200-500{ }^{\circ} \mathrm{C}$. The increase in the fixation of particles of sprayed material on the surface is likely to be related to the increase in their ductility with temperature increasing.

It is seen from (Figures 1) that the structure of coating material is inhomogeneous. Bright local areas and dark-grey inclusions of different sizes are observed in the grey matrix. The composition of matrix and inclusions were identified by EDS. It was found that the grey matrix (1) of coating material almost is pure aluminum. Bright local areas (2) inside and on the surface of grey matrix are almost pure zinc. Dark-grey angular inclusions (3) are corundum. Figure 3 shows microstructure of substrate with coating and EDS maps of $\mathrm{Nd}, \mathrm{Fe}, \mathrm{Al}, \mathrm{Zn}$, and O distribution.

It is seen from (Figures 1,3) that zinc forms local areas within aluminum matrix that is the coating base. The chemical interaction between $\mathrm{Al}$ and $\mathrm{Zn}$ is absent. No alloy-formation between these elements is observed. Corundum particles are sufficiently uniformly distributed in the coating material. The size of corundum particles in coatings sprayed at $100-300^{\circ} \mathrm{C}$, as a rule, is lower than that of corundum particle present in the initial powder mixture. It is likely that initial corundum particles speed up to high rates by carrier gas flow break upon collision with the substrate. A portion of these broken corundum particles ricochet off the deposited surface (substrate surface) and a portion of broken particles remain within the coating material. As the spraying temperature increases $\left(400\right.$ and $500{ }^{\circ} \mathrm{C}$ ), the sizes and amount of corundum particles present in the coating material markedly increase. The increase in the corundum particle size and amount are likely to be related to the fact that $\mathrm{Al}$ and $\mathrm{Zn}$ particles soften and adhere to movable corundum particles. As a result, upon collision with the substrate surface, corundum particles fix within the coating material rather than split and ricochet off the surface. 

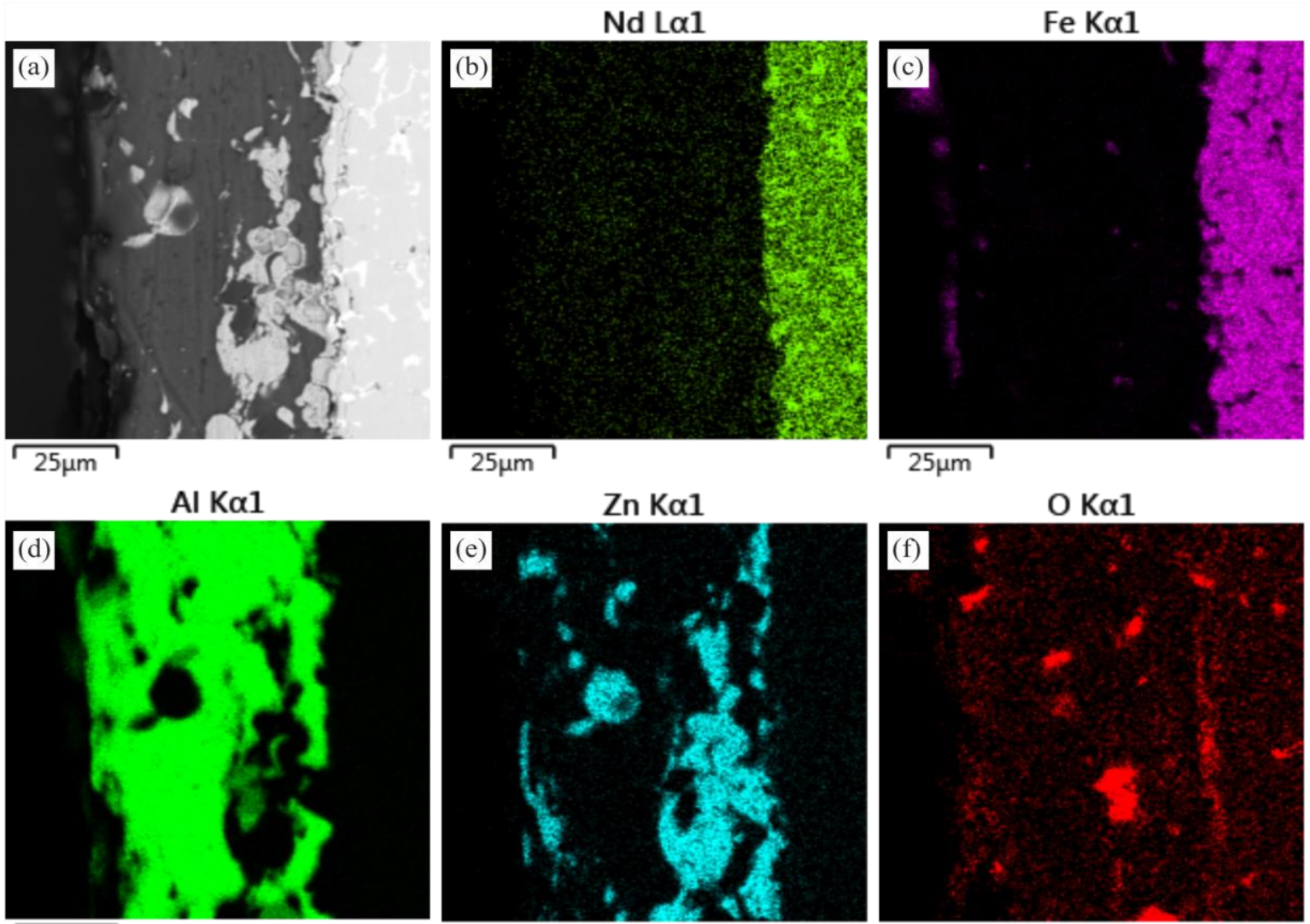

$\mathrm{Zn} \mathrm{K \alpha 1}$

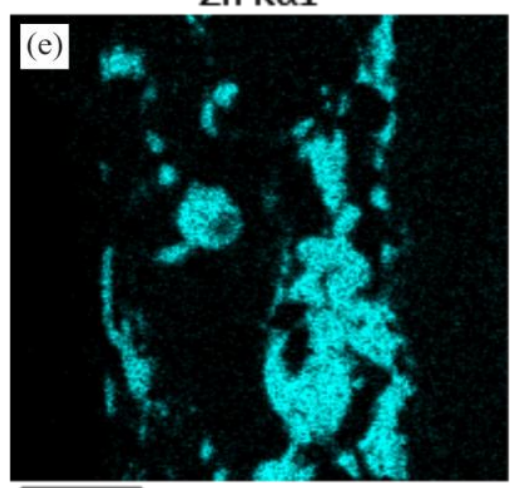

$\longdiv { 2 5 \mu m }$

$\mathrm{O} K \alpha 1$

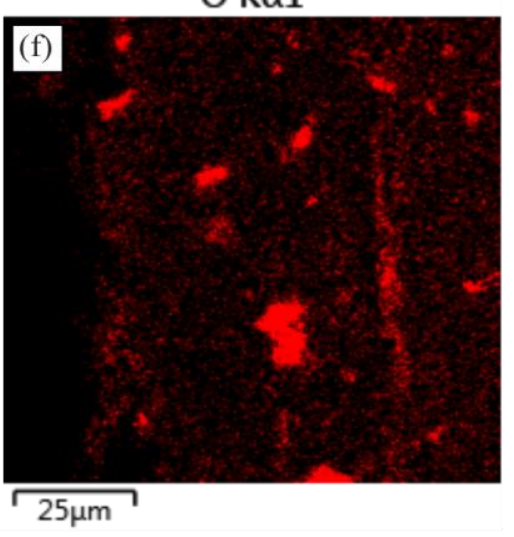

Figure 3 (a) SEM image and EDS maps of cold sprayed aluminum-zinc coating: (b) Nd, (c) Fe, (d) Al, (e) Zn, and (f) $\mathrm{O}$.

To confirm the results of metallographic studies, the quantitative analysis of the coatings prepared in regimes $100-500^{\circ} \mathrm{C}$ was performed. Figure 4 shows results of the analysis.

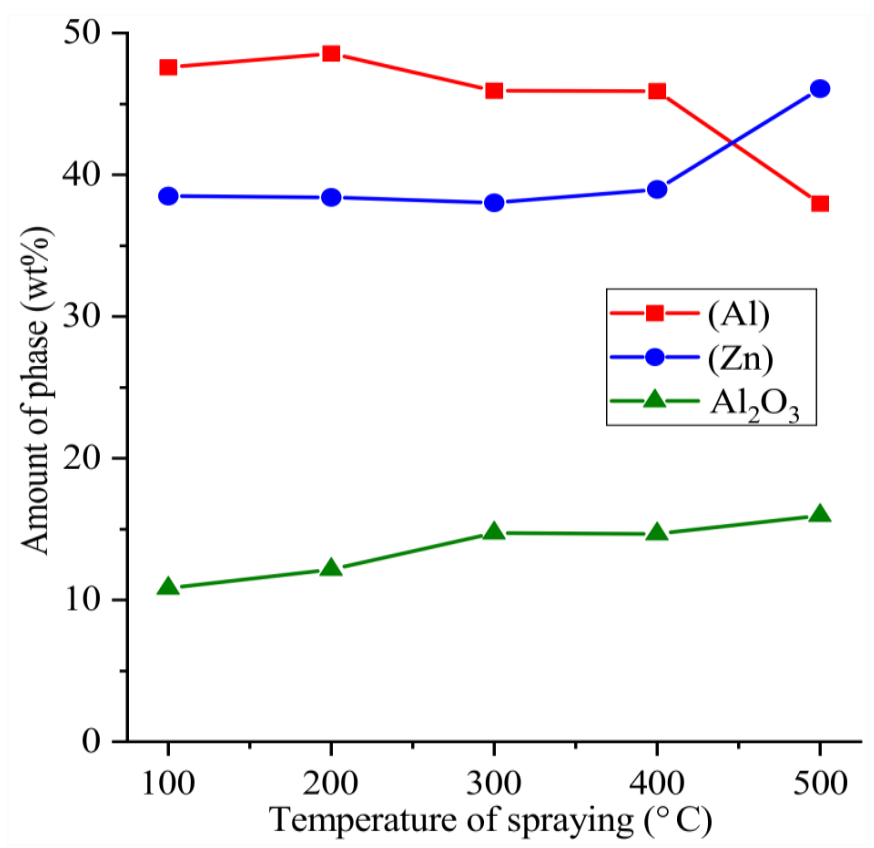

Figure 4 Variation of phase compositions of coatings cold sprayed at various temperatures 
It is seen from (Figure 4) that, in all cases, the material of cold sprayed coatings is characterized by the presence of three phases; these are $\mathrm{Al}, \mathrm{Zn}$, and $\mathrm{Al}_{2} \mathrm{O}_{3}$. As the spraying temperature increases from 100 to $500{ }^{\circ} \mathrm{C}$, the aluminum content in the material decreases from 47.6 to $38.0 \%$, whereas the zinc content increases from 38.5 to $46.1 \%$. The corundum content increases from 10.8 to $\sim 16.0 \%$. It should be noted that, in this case, the embrittlement of coating takes place.

The adhesion strength of the studied cold sprayed aluminum-zinc coatings, which was determined by Scratch testing, showed that, as the load increases from 0 to $25 \mathrm{~N}$, throughout the indenter trajectory, in any case, the contact of coating with substrate was not disturbed. However, for samples prepared at spraying temperatures of 400 and $500{ }^{\circ} \mathrm{C}$, spallings formed by indenter appear on the surface of coating; this indicates the increase in the brittleness of coating.

The first stage of corrosion tests performed in the KST-1 salt spray chamber at a temperature of $35 \pm 5{ }^{\circ} \mathrm{C}$ showed the absence of any corrosive damages of the base (protected) material for all studied samples for the whole period of tests. At the second stage of tests, traces of corrosion on the base material appear only on the sample prepared at $100^{\circ} \mathrm{C}$ after 20 days of tests. Centers of corrosion attack were observed at the edge of permanent magnet. Magnets with coatings applied at temperatures of $200-500^{\circ} \mathrm{C}$ exhibit no traces of corrosion upon the completion of the second stage corrosion tests.

\section{CONCLUSIONS}

The properties of cold sprayed aluminum-zinc coatings applied on the surface of $\mathrm{Nd}$-Fe-B permanent magnets depend on the temperature conditions of spraying.

At all temperature conditions of spraying, the coatings densely adhere to the coated surface; no exfoliations are observed.

The increase in the spraying temperature from 100 to $500^{\circ} \mathrm{C}$ does not lead to the alloy formation between $\mathrm{Al}$ and $\mathrm{Zn}$ particles. In all cases, the coatings consist of a mechanical mixture of $\mathrm{Al}, \mathrm{Zn}$, and $\mathrm{Al}_{2} \mathrm{O}_{3}$ particles. No new phases form in the coating.

The increase in the spraying temperature leads to a slight increase in the $\mathrm{Zn}$ content and a decrease in the $\mathrm{Al}$ content in the coating composition and also to the substantial increase in the amount of corundum particles and their sizes.

The adhesion strength of cold sprayed aluminum-zinc is high. A scratch force of $25 \mathrm{~N}$ does not cause destruction of coating and does not lead to the exfoliation of coating from the substrate (sprayed surface). The increase in the spraying temperature does not lead to a decrease in the adhesion strength of coating; however, in this case, the brittleness of coating increases. This fact is likely to be related to the increase in the amount of corundum particles in the material and increase in their sizes.

All cold sprayed aluminum-zinc coatings prepared at temperatures of $200-500{ }^{\circ} \mathrm{C}$ ensure the adequate protection of $\mathrm{Nd}-\mathrm{Fe}-\mathrm{B}$ magnets against corrosion; however, the recommended spraying temperature is equal to $200{ }^{\circ} \mathrm{C}$ since the higher temperatures lead to the embrittlement of coatings.

\section{REFERENCES}

[1] BUSCHOW, K.H.J., DE BOER, F.R. Phisics of Magnetism and Magnetic Materials. New York: Kluwer Academic Publishers University, 2004. p. 179.

[2] COEY, J.M.D. Magnetism and Magnetic Materials. Unated Kindom: Cambridge University Press, 2010. p. 616.

[3] BELYAEV, I.V. "Hard Magnetic Materials," in "High-Purity Substances". In Nauchnyi mir 2018. Moscow: part IV, ch. 38, pp. 979-995. - ISBN 978-5-91522-463-5.

[4] MITCHELL, P. Corrosion protection of NdFeB magnets. JEEE Trans. Magnets. 1990, vol. 26, no. 5, pp. 19331935. 
[5] WALTON, A., SPEIGHT, J.D., WILLIAMS, A.J., HARRIS, J.A. A zinc coating method for Nd-Fe-B magnets. J. Alloys Comp. 2000, vol. 306, no. 1-2, pp. 253-261.

[6] FIDLER, J., SCHREFL, T., HOEFINGER, S., HAJDUGA, M. Recent developments in hard magnetic balk materials. J. Phys., Condens Matter. 2004, vol. 16, no. 5, pp. 455-470.

[7] BELYAEV, I.V., STEPNOV, A.A., KUTEPOV, A.V., SPRYGIN, G.S., GRIGOROVICH, K.V., KOLCHUGINA, N.B., KURSA, M. Anticorrosive coatings for Nd-Fe-B permanent magnets. Fiz. Khim. Obrab. Mater. 2011, no. 5, pp. 1518.

[8] BELYAEV, I.V., KOLCHUGINA, N.B., SPRYGIN, G.S., KURSA, M., LASEK, S., KONECNA, K. Structure and corrosion properties of Al-Zn protective coating for Nd-Fe-B permanent magnets. Metallurgical Journal. 2012 , vol. 64(3), pp. 59-65. 